\title{
Effective protection may alter the look of Venice
}

\section{Those seeking to rescue Venice are caught between the devil and the deep-blue sea.}

Sir - Your News Feature "Save our city!" (Nature 424, 608-609; 2003) reviews the dilemma faced in selecting a large-scale engineering project to protect Venice, to be implemented and financed by the Italian government. I can see benefits in both of the two major projects discussed: the MOSE series of moveable gates, and the scheme to separate the city from its lagoon and the sea.

Unfortunately, the first option is likely to serve only as a temporary protective measure for a century or two and cause collateral problems, such as increased pollution. The second, on the other hand, will permanently alter the configuration and setting of the Venice we know, a city that is charmed and recognized by its lagoon.

Various ancient Greek coastal cities, some with canals and constructed centuries earlier than Venice, are now completely submerged, such as Herakleion off the coast of Egypt. They, too, faced problems of insufficient protection against water surges and sea-level rise, and subsidence caused by the building of monumental structures on inadequate foundations. Towards the end of their active history, when the sea level rose above the base of the buildings, structures toppled increasingly rapidly until the cities were finally submerged.
In geological terms, these cities were similar to Venice. Considering what befell them, the opposite of the geological tenet "the present is key to the past" may well apply to Venice. Perhaps a longerterm, more secure approach would be one involving comprehensive Netherlands-type 'polder' dyke constructions, with seawater being pumped out of the encircled city, water maintained in the canals, and those unique structures reinforced, where possible, by deep pilings.

Jean-Daniel Stanley

Geoarchaeology Program, National Museum of Natural History, Smithsonian Institution, Washington DC 20560, USA

\section{How do impact factors relate to the real world?}

Sir - I have read with interest your debate on the impact of scientific work (for example, Nature 422, 259-261; 2003, Nature 423, 479-480 \& 585; 2003 and Nature 424, 14; 2003) but I do not agree with the position taken by Adam Lomnicki (Nature 424, 487; 2003).

The problem is that Lomnicki and others established their careers at a time when competition among scientists had a different meaning. I am a young scientist and like everyone I would like to discover something interesting and new. However, when my colleagues and I discuss biological problems we always think about impact factors.

Recently, my friends wondered where to send their new paper - to journal X with an impact factor of 1.4 , or to journal $\mathrm{Y}$ with an impact factor of 1.8. After 10 years, the average paper will be cited 14 times in journal $\mathrm{X}$ and 18 times in journal $\mathrm{Y}$ (assuming a constant citation rate, which is not the case, of course). Thus we compete furiously for just a few more citations, as the impact factor of most journals does not exceed three.

As Lomnicki states, citations are statistical processes, but even very good papers are cited only a few times. The question is whether the difference between 10 and 20 citations can really change our knowledge and understanding of nature.

Journals as well as scientists compete for impact factors. A journal that wants a higher impact factor has to encourage authors to publish in it, but with more papers coming in, more must be rejected. Generally, authors want to publish in journals with the highest possible impact factor, but it is very difficult for most journals to improve their impact factors as most submitted papers have been rejected by better journals.

Impact factors provide an easy way to assess our achievements. But we do not know if small differences in citation number are valid indicators of our work, or how citations are related to the real world and solving its problems.

Piotr Skórka

Institute of Environmental Sciences, Jagiellonian University, ul. Gronostajowa 3, 30-387 Kraków, Poland

\section{Pointless suffering of animals can be avoided}

Sir — In the News article "Agony for researchers as mix-up forces retraction of ecstasy study" (Nature 425, 109; 2003) the 'agony' of the embarrassed researchers was dwarfed by that of their primate subjects.

From an animal-welfare standpoint, the affair was tragic. From a scientific standpoint, it was pointless. After all, the researchers themselves have noted that extensive evidence from animal studies already shows that methylenedioxymethamphetamine (MDMA, or ecstasy) is dangerous. If more proof of its recreational effects is needed, scientists should focus on the many humans who use such drugs.

Ethical and non-invasive studies are easily conducted and, in fact, are already being carried out to allow scientists to detect early signs of Parkinson's disease or other neurological effects in drug users.
In research currently being conducted by J. H. Atkinson at the University of California, San Diego, human users of methamphetamine (speed) - the drug accidentally used in the 'ecstasy study' are examined for neurological and cognitive function and other clinical features. A similar strategy would apply to the study of MDMA.

Neal D. Barnard

Physicians Committee for Responsible Medicine, 5100 Wisconsin Avenue, Suite 400,

Washington DC 20016, USA

\section{JET at risk if Europe can not afford to pay for ITER}

Sir - I agree with much of what Richard Buttery says in his letter (Nature 424, 995; 2003) about the Joint European Torus (JET), but I must point out that he has quoted my statement (Nature 424, 4; 2003) out of context. I was asked by Nature to comment on the situation that might occur if there were no substantial increase in the fusion budget in the Seventh Euratom Framework Programme. I mentioned the possible closure of JET in the context of there being insufficient money to finance the European contribution to ITER.

\section{A. M. Bradshaw}

Max-Planck-Institut für Plasmaphysik,

Boltmannstrasse 2, Garching/Greifswald, Germany

\section{correspondence}

Contributions to Correspondence may be submitted to corres@nature.com. They should be no longer than 500 words, and ideally shorter. Published contributions are edited. 